\title{
In Memoriam Jerome Bruner (1915-2016)
}

\author{
In Memoriam Jerome Bruner (1915-2016)
}

\author{
Walter L. Arias Gallegos \\ Universidad Católica San Pablo, Arequipa, Perú
}

Recibido: 11-10-16

Aprobado: 25-10-16

\section{Corresponding author}

Email: walterlizandro@hotmail.com
How to cite:

Arias, W. (2016). In Memoriam Jerome Bruner (1915-2016). Propósitos y

Representaciones, 4(2), 427-436. Doi: http://dx.doi.org/10.20511/pyr2016.v4n2.127

(C) Universidad San Ignacio de Loyola, Vicerrectorado de Investigación y Desarrollo, 2016. (๘) BY.NC-ND Este artículo se distribuye bajo licencia CC BY-NC-ND 4.0 Internacional (http://creativecommons.org/licenses/by-nc-nd/4.0/). 


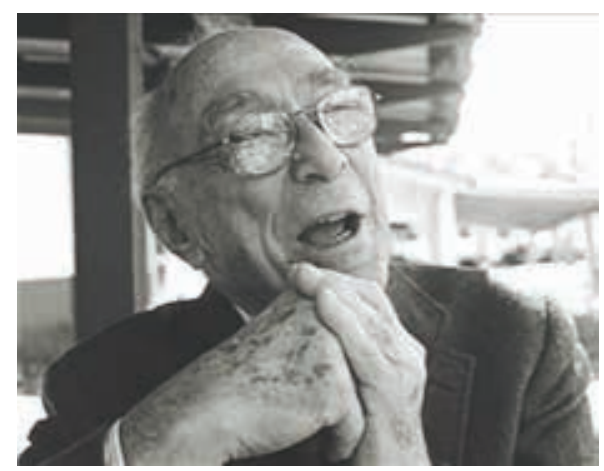

El 5 de junio último, Jerome Bruner falleció en New York, de manera imprevista, pero a la vez indolora y apacible. Bruner ha sido uno de los psicólogos más influyentes del siglo XX a través de su labor académica en los campos de la psicología educativa y la psicología narrativa, donde ha alcanzado notoriedad, pero también se ha dedicado a la psicología militar, a la psicología culturalista $y$, más recientemente, a la psicología forense (Arias, 2015).

Jerome Bruner nació el 1 de octubre de 1915 en New York, de modo que el año pasado cumplió 100 años de edad. Estudió Psicología en la Universidad de Duke, y luego trabajó en la Universidad de Harvard, donde realizó una labor muy importante al promover el desarrollo de la psicología cognitiva (Arias, 2005). Así, la publicación de su libro A study of thinking marcó el inicio del movimiento cognitivo en 1956 (Bruner, Goodnow y Austin, 2003). Además fundó, junto con George Miller, el Centro de Estudios Cognitivos, que sirvió para hacer investigación cognitiva sobre diversos temas (Greenwood, 2011). Este prestigioso centro fue visitado por importantes figuras con fuerte impacto en la psicología de su tiempo, como Noam Chomsky, Jean Piaget, Alexander Luria, John von Newman, Norbert Wiener (Temporetti, 2010).

Entre los temas que Bruner ha estudiado a lo largo de su vida, podemos mencionar la percepción, la formación de conceptos (Bruner et al., 2003), el protolenguaje (Bruner, 2002), la estructura cognitiva (Bruner, 1973), el andamiaje (Wood, Bruner y Ross, 1976), etc. Su obra tuvo un impacto muy grande en educación a través de la reforma educativa norteamericana con las conferencias Woods Hole de 1959 (Bruner, 1968) y el programa Head Start, en el que colaboró con Urie Bronfenbrenner (Guilar, 2009). Abogó por 
una sólida teoría de la enseñanza que reposara en la pedagogía activa y el acercamiento de los estudiantes al mundo de la ciencia (Bruner, 1987).

Buena parte de su obra ha descansado en las ideas de Piaget, Luria y Vigotsky, en aspectos como las etapas del desarrollo enactiva, icónica y simbólica, así como en la construcción de la identidad a partir de la narrativa. $\mathrm{Su}$ orientación cognitiva, su enfoque constructivista y su postura culturalista han dado forma a sus múltiples ideas, que ha sabido expresar con originalidad, como la teoría del "New Look" (Bruner y Goodman, 1947), la teoría del aprendizaje por descubrimiento (Bruner, 1961) y el modelo evolutivo del crecimiento cognitivo (Bruner, 1966).

Asimismo, ha sido protagonista de la revolución cognitiva y de la revolución cultural. En ese sentido, se dedicó, desde hace más de cuatro décadas, al análisis de cómo el lenguaje nos permite construir realidades nuevas como nuestro propio yo (Bruner, 2004). La narrativa es, para él, la puerta de la cultura y una ventana psicológica de nuestro mundo interior (Bruner, 2003).

Entre sus obras más difundidas tenemos: The process of education, Toward a theory of instruction, The relevance of education, Process of cognitive growth, Actual minds and possible worlds, Acts of meaning, Minding the law, Making stories, etc. Sus artículos de investigación están ubicados en las mejores revistas de psicología, como American Psychologist, Child Development, Harvard Educational Review, Journal of Abnormal and Social Psychology, Social Research, etc.

Bruner ha sido presidente de la APA en 1964 y fue galardonado con la medalla CIBA en 1974. Igualmente, recibió el Premio Internacional Balzan en 1987. Ha sido Doctor Honoris Causa de la Universidad de Yale, la Universidad de Columbia, La Sorbona de París, la Universidad Autónoma de Madrid, la Universidad de Berlín y la Universidad de Roma, entre otras.

Su vida ha sido, además, un ejemplo de lucha por defender los ideales más nobles del ser humano, de persistente y original trabajo académico, así 
como de creativa y profunda lucidez, que lo caracterizó hasta los últimos momentos de su existencia. Desde aquí nos despedimos de él y reafirmamos nuestro compromiso por continuar difundiendo su obra y seguir sus pasos en la senda de la psicología académica. Descansa en paz, Jerome Bruner.

\section{Referencias}

Arias, W. L. (2005). Psicólogos hombres de ciencia. Arequipa: Editorial Faraday.

Arias, W. L. (2015). Jerome Bruner: 100 años dedicados a la psicología, la educación y la cultura. Revista Peruana de Historia de la Psicología, $1,59-79$.

Bruner, J. S. (1961). The act of discovery. Harvard Educational Review, 4, 21-32.

Bruner, J. S. (1966). Toward a theory of instruction. Cambridge: Harvard University Press.

Bruner, J. S. (1968). El proceso de la educación. México: Unión Tipográfica Editorial Hispano Americana.

Bruner, J. S. (1973). Beyond the information given. New York: Norton.

Bruner, J. S. (2002). Acción, pensamiento y lenguaje. Madrid: Alianza Editorial.

Bruner, J. S. (1987). La importancia de la educación. Barcelona: Paidós educador.

Bruner, J. S. (2003). La fábrica de historias. Derecho, literatura y vida. Buenos Aires: Fondo de Cultura Económica.

Bruner, J. S. (2004). Life as narrative. Social Research, 71(3), 691-710.

Bruner, J. S. \& Goodman, C. C. (1947). Value and need as organizing factors in perception. Journal of Abnormal and Social Psychology, 42(1), 33-44.

Bruner, J. S.; Goodnow, J. J. \& Austin, G. (2003). El proceso mental en el aprendizaje. Madrid: Narcea.

Greenwood, J. D. (2011). Historia de la psicología. Un enfoque conceptual. México, D. F.: McGraw-Hill. 
Guilar, M. E. (2009). Las ideas de Bruner: de la revolución cognitiva a la revolución cultural. Educere, 13(44), 235-241.

Temporetti, F. (2010). La psicología en construcción... y una pedagogía también. Psyberia, 2(3), 7-40.

Wood, D.; Bruner, J. S. y Ross, G. (1976). The role of tutoring in problem solving. Journal of Child Psychology and Psychiatry, 17, 89-100. 